\title{
University and College Travel for Students with Mobility Impairment(s) in the Greater Toronto and Hamilton Area, Canada
}

\author{
Jordan Aharoni', Ron Buliung ${ }^{2}$ (), Raktim Mitra $^{3}$ (i) \\ ${ }^{1}$ Geography and Planning, University of Toronto, ${ }^{2}$ Geography, Geomatics and Environment, UNIVERSITY OF TORONTO MISSISSAUGA, ${ }^{3}$ School of Urban and \\ Regional Planning, Ryerson University \\ Keywords: impairment(s), commuting, inequality, college, university, transportation, disability, mobility \\ 10.32866/001c.18630
}

\section{Findings}

Students with disabilities have largely been left out of travel behaviour research.

We examined differences in student reported transport mode share, and perceptions about commuting impacts on education, between students with and without mobility impairment(s). Data are taken from the 2019 StudentMoveTO survey of university and college student travel in the Greater Toronto and Hamilton Area. Students with mobility impairment(s) reported greater use of modified vehicles and shared modes, particularly with other household members. Students with mobility impairment(s) were also more likely to report that commuting discourages them from coming to campus and limits their academic success.

\section{Research Question and Hypothesis}

Students with disabilities are underrepresented in research about postsecondary students' experiences with transport and other aspects of postsecondary education (Holloway 2001; Soorenian 2013; Vickerman and Blundell 2010). The right of equal access to education for persons with disabilities is guaranteed under Canada's Charter of Rights and Freedoms, the United Nations Convention on the Rights of Persons with Disabilities (signed by Canada in 2010), the Education Act in the Province of Ontario (the provincial setting for this research), and within other pieces of legislation.

What do we mean when we use the term "disability" in this work? We take up the social model, where disability is understood as not being located within the body, rather it is produced by society. Our environment, communities, and institutions produce disability and disabling experiences (Oliver 1990). Our use of the word "impairment(s)" in the paper's title speaks to the clinical mobility situation of each student, rather than disability which, in alignment with the social model, is produced externally. In the context of transport technologies and services, design and operation may indeed focus on individual impairment(s), i.e., what the body can or cannot do (walking, seeing, hearing). When services are inadequate, when they produce inequality for persons with disabilities, they are disabling or produce disabling experiences.

In this paper, we explore and compare how students with mobility impairment $(s)$ and other students travel to university or college, and differences in their perceptions about how their commuting affects their education access and experiences. The work is set in the Greater Toronto and Hamilton Area (GTHA), Canada's largest urbanized region. The primary research questions 
are: (1) how do students with mobility impairment(s) commute to universities and colleges? And (2) do students with mobility impairment(s) perceive commuting as a barrier to achieving their education and extracurricular goals? If there is some indication of difference between the experiences of students with and without mobility impairment(s), then a deeper analysis of transport demand and service provision will be required to attend to the ways in which transport may be disabling in this context.

\section{Methods and Data}

Data are drawn from the 2019 StudentMoveTO survey, a large-scale collaborative research program established to better understand the activitytravel behavior of post-secondary students in the GTHA (Mitra et al. 2020). The 2019 survey was distributed to all full- and part-time students (with some exceptions) at six universities and four community colleges across the GTHA. The survey invitation was sent via email to a random group of students everyday from October 1 to November 30. Students were asked to choose the main means of transportation used for school travel on a typical fall day, accounting for the longest distance travelled. A total of 18,513 complete responses were received with a $6 \%$ response rate.

The online survey platform complied with the Accessibility for Ontarians with Disabilities Act (AODA) requirements. The survey included one question that enabled students to self-identify with mobility-related impairment(s). The question was developed in consultation with the Accessibility Coordinator at Ryerson University: "Are you a person with disability who regularly uses a wheelchair, walker or other mobility aid?". Because of this, there is an implication that students with other types of impairment(s) might be counted as a student without disabilities. A total of 149 students indicated having a mobility impairment(s). Students with mobility impairment(s) constituted $0.8 \%$ of the overall sample, with some schools reaching a rate closer to $2 \%$. Data from the Canadian Survey on Disability (CCD) indicate that $1.5 \%$ of Canada's population, aged 15-24 years, live with mobility impairment(s) (Statistics Canada 2017).

\section{Findings}

Students were asked to report on their typical commute mode for the fall semester, these data are summarized in Figure 1. Transit bus and walking were the most common school travel modes for students with and without mobility impairment(s). Subway/rail transit was the next most frequently used mode. The gap in subway/RT use between groups was not entirely surprising given lack of accessible stations and problems with equipment (e.g., elevator failures), a problem that is not unique to our region (Grisé et al. 2019; Nanowski 2017). Students with mobility impairment(s) appear to have a larger share of their trips conducted with other household members (labelled as "Drive w/ household pass. or "Pass. w/household driver") and in modified private vehicles (labelled as "Access. Vehicle Driver" or "Access. Vehicle Pass."), than other 


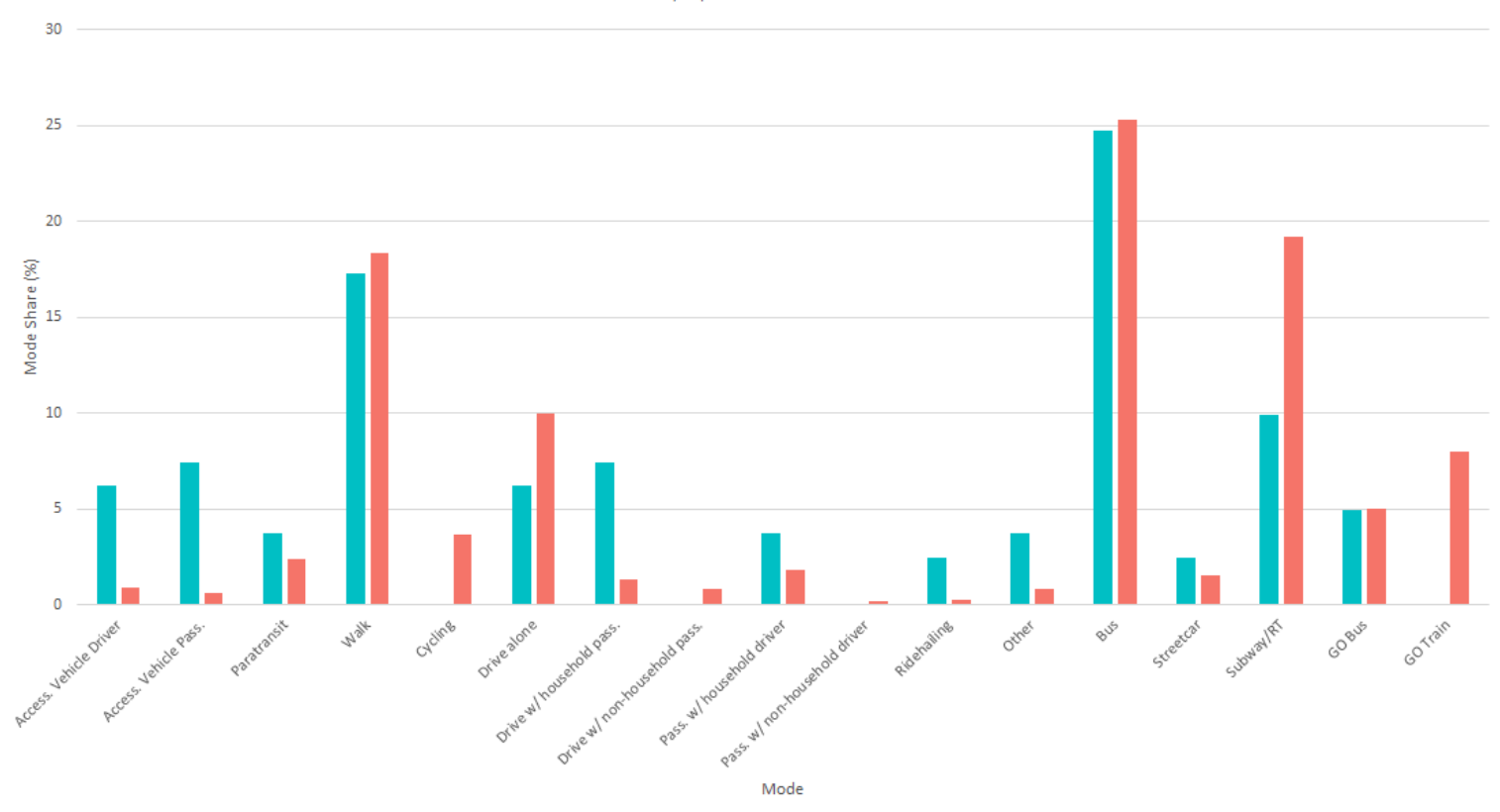

Figure 1: Typical fall mode share for students with and without mobility impairment(s).

students. Our exploratory examination raises interesting questions about the care work of other household members in facilitating access to education, how and where shared and/or specialized modes are being accommodated on campus, and how problems of accessibility and design (i.e., subways) may limit access to transit options that reliably work for students with mobility impairment(s).

Findings regarding our second research question concerning the relationship between transport and commuting on education and campus life are summarized in Figure 2. Students were asked six questions and could respond either "Yes" or "No". We were concerned to discover quite striking differences in how students with and without mobility impairment(s) responded to these questions. More specifically, we found statistically significant differences in the responses between groups for the first ("Commute discourages from coming to campus") and last ("Commute is a barrier to academic success") questions at $\mathrm{p}<.01$, potentially indicating the production of unequal opportunity for academic engagement and success for students with mobility impairment(s) due to problems within the transport systems facilitating access. Even where the data indicate similar response rates, i.e., commuting and participation in activities/events, we suspect that "why" students report that commuting is a barrier to activity participation is quite different between the two populations. For example, the Canadian Human Rights Commission's landmark report, "Left Out: Challenges Faced by Persons with Disabilities in Canadian Schools", suggests that students with disabilities face barriers that include lack of disability accommodation and support, and lack of services and funding 

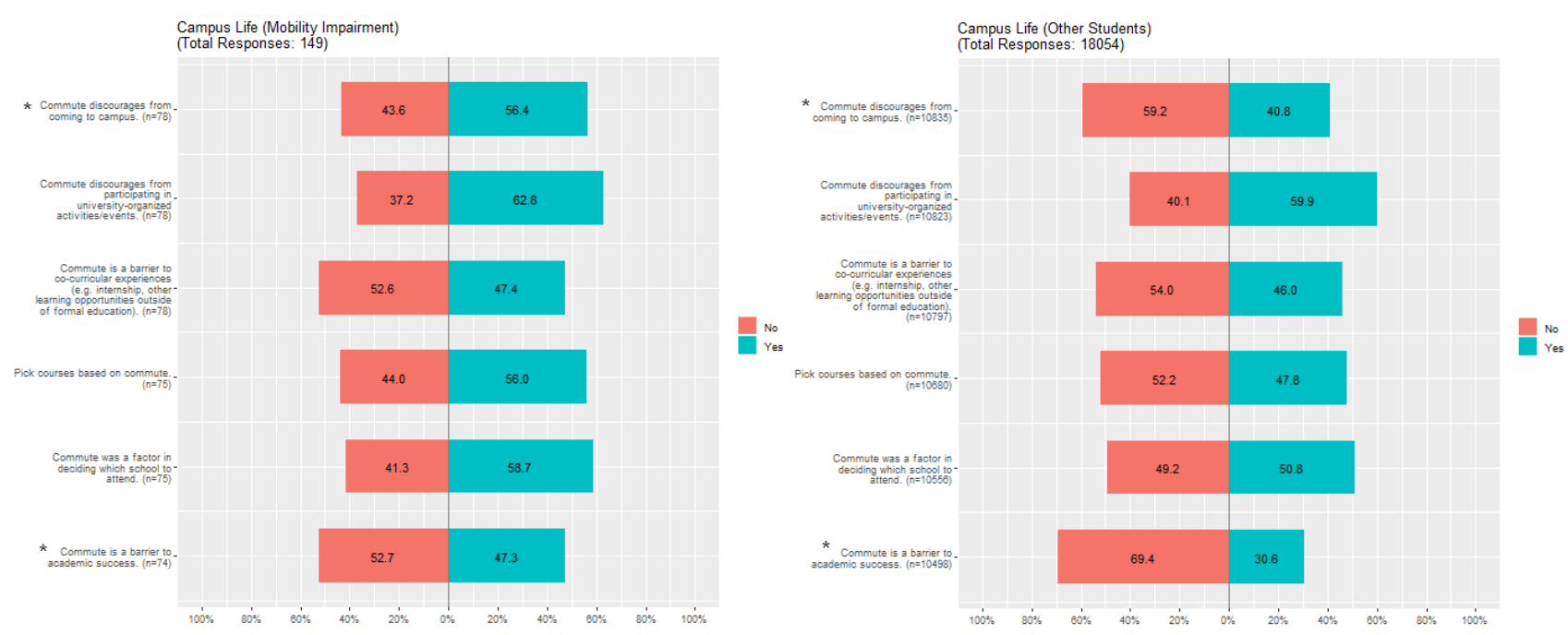

Figure 2: Student responses to questions about their perceptions about commuting and academic success and campus life. ${ }^{*}$ Indicates significant difference at $\mathrm{p}<.01$ between responding students with and without mobility impairment(s).

(Canadian Human Rights Commission 2017). Overall, our findings begin to highlight the importance of taking a closer look into the ways in which transport may produce disabling experiences for students in post-secondary education.

\section{Acknowledgement}

The StudentMoveTO survey was supported by a Social Sciences and Humanities Research Council of Canada (SSHRC) Partnership Development Grant. Authors would like to acknowledge Ms. Heather Willis, Accessibility Coordinator at Ryerson University, for her feedback on the survey.

Submitted: November 28, 2020 AEDT, Accepted: January 04, 2021 AEDT

This is an open-access article distributed under the terms of the Creative Commons Attribution 4.0 International License (CCBY-SA-4.0). View this license's legal deed at https://creativecommons.org/ licenses/by-sa/4.0 and legal code at https://creativecommons.org/licenses/by-sa/4.0/legalcode for more information. 


\section{REFERENCES}

Canadian Human Rights Commission. 2017. "Left out: Challenges Faced by Persons with Disabilities in Canada’s Schools.” Ottawa. https://www.chrc-ccdp.gc.ca/eng/content/left-outchallenges-faced-persons-disabilities-canadas-schools.

Grisé, Emily, Geneviève Boisjoly, Meadhbh Maguire, and Ahmed El-Geneidy. 2019. "Elevating Access: Comparing Accessibility to Jobs by Public Transport for Individuals with and without a Physical Disability." Transportation Research Part A: Policy and Practice 125 (xxxx): 280-93. https://doi.org/10.1016/j.tra.2018.02.017.

Holloway, Sarah. 2001. "The Experience of Higher Education from the Perspective of Disabled Students." Disability and Society 16 (4): 597-615. https://doi.org/10.1080/09687590120059568.

Mitra, Raktim, Khandker Nurul Habib, Matti Siemiatycki, Roger Keil, and Jeremy Bowes. 2020. "StudentMoveTO - From Insight to Action on Transportation for Post-Secondary Students in the GTHA: 2019 Transportation Survey Findings.” http://www.StudentMoveTO.ca.

Nanowski, Natalie. 2017. "Wheel-Trans Users Fear New Program Will Force Them to Use Inaccessible TTC.” CBC News, September 20, 2017.

Oliver, Mike. 1990. "The Social Construction of the Disability Problem." In The Politics of Disablement, 78-94. London: Macmillan Education UK. https://doi.org/10.1007/ 278-1-349-20895-1_6.

Soorenian, Armineh. 2013. "Housing and Transport: Access Issues for Disabled International Students in British Universities." Disability and Society 28 (8): 1118-31. https://doi.org/10.1080/ $\underline{09687599.2012 .758033 .}$.

Statistics Canada. 2017. "Canadian Survey on Disability.” https://www150.statcan.gc.ca/t1/tbl1/ en/tv.action?pid $=1310037401$ \&pickMembers $\% 5 B 0 \% 5 \mathrm{D}=1.1$.

Vickerman, Philip, and Milly Blundell. 2010. "Hearing the Voices of Disabled Students in Higher Education." Disability and Society 25 (1): 21-32. https://doi.org/10.1080/09687590903363290. 